Cad. Líng. Lit. Hebr., n. 15, p. 10-16, 2017

\title{
A CONDIÇÃO JUDAICA - VOCÊ NÃO SE LIVRA DELA (MOACYR SCLIAR)
}

Berta Waldman*

Em A nossa frágil condição humana, livro organizado por Regina Zilberman, estão reunidas 68 crônicas de Moacyr Scliar, publicadas entre 1977 e 2010 e destinadas ao jornal de gaúcho Zero Hora ${ }^{1}$, com o qual o autor colaborou desde a primeira metade dos anos 1970 até a sua morte.

Esse terceiro volume de crônicas resulta do que Scliar define como "o olhar do judeu", aquele que, em suas palavras, "vê o que os outros não veem" - depreendendo-se, dessa forma, uma condição judaica, isto é, um modo como o judeu se define e é definido na diáspora e em Israel. A partir desse enfoque origina-se o objeto de minha análise, que tem como pressuposto o papel fundamental da produção de Moacyr Scliar na representação da condição judaica nas literaturas brasileira e latino-americana.

Uma questão importante a se destacar é a de que houve dois momentos distintos da produção de Scliar em sua relação com o leitor. Inicialmente, as crônicas eram publicadas em jornal, mas mudaram de "habitat" quando selecionadas e impressas em livro, transpondo-se da imediatez de um veículo à permanência do outro. Além disso, se o primeiro amplia o público leitor, o segundo é mais seletivo.

Fruto do jornal, a crônica é um gênero literário que se caracteriza por estar perto do dia a dia, seja nos temas escolhidos, seja em sua linguagem despojada e coloquial. Mais do que isso,

\footnotetext{
* Professora de Literatura Hebraica na Faculdade de Filosofia, Letras e Ciências Humanas da Universidade de São Paulo.

${ }^{1}$ No Zero Hora foram publicadas mais de cinco mil crônicas do autor.
} 
ela surge inesperadamente como um instante de alívio para o leitor fatigado com a frieza da pretendida objetividade jornalística.

De extensão limitada, essa pausa se caracteriza por se voltar contra as tendências fundamentais do meio em que aparece. Se a notícia, tradicionalmente, deve ser objetiva e impessoal, a crônica é, assumidamente, subjetiva. Se a linguagem jornalística deve ser precisa e enxuta, a crônica pode ser impressionista, digressiva, lírica e, às vezes, irônica. Se o jornalista deve ser metódico e claro, o cronista pode conduzir o leitor sem que este perceba, movido, aparentemente, pelo método menos metódico que existe: o do assunto puxa assunto. A crônica não é, portanto, apenas "fillha" do jornal. Ela é também o antídoto que o próprio periódico produz para garantir sua variedade e leitura.

Embora a notícia de jornal possa ser efêmera, a crônica tem um tempo de vida que depende de seu interesse imediato e de suas qualidades de construção. Apesar do foco no tempo presente, matérias, por exemplo, vinculadas ao conflito árabe-israelense continuam em pauta até hoje, passados tantos anos desde a publicação da crônica de Scliar no jornal. Isso porque o conflito perdura de diferentes modos até agora. Mas não é dos conflitos que vou tratar e sim de como alguns aspectos do judaísmo motivaram as crônicas de Scliar. Vale lembrar, citando a apresentação de Zilberman ao A nossa frágil condição humana, que o autor propôs a representação mais completa da religião judaica e da personagem judia na literatura brasileira, abrindo caminho para escritores de outras gerações.

As escolhas temáticas das crônicas de Scliar variam, indo da política à literatura, e os países de seu campo analítico são o Brasil e o Estado de Israel. Além de tratar do convívio árabe-israelense que precisa, segundo ele, ser reconstruído permanentemente, o autor aborda núcleos temáticos como a situação da literatura hebraica contemporânea, a ética judaica 
Cad. Líng. Lit. Hebr., n. 15, p. 10-16, 2017

fundada na justiça e no equilíbrio, a representação do Holocausto e seus horrores, entre outros temas.

No que tange à literatura hebraica contemporânea, ele destaca os conjuntos de ensaios "Holocausto e literatura" (p. 168-172) e "Mensagem de esperança" (p. 173-174), além de três autores que escreveram sobre o tema em Israel: Aharon Appelfeld, David Grossman, A. B. Yehoshua. Nesta seleção, Amós Oz e o poeta Yehuda Amichai não foram incluídos, por não terem sido encontrados para as entrevistas.

Ainda sem pátria, o povo judeu fez do livro (a Bíblia, o Talmud) a sua pátria. Mas, quando esta ganha configuração geopolítica com a fundação do Estado, a mudança traz transformações que ecoam na literatura e provocam a emergência de um grupo de escritores, que se expressam numa nova (antiga) língua, com nova tonalidade e novo ponto de vista.

É exatamente essa camada da realidade a responsável pela relação que se trava entre o escritor judeu-brasileiro Moacyr Scliar e os autores nascidos ou tornados israelenses dos quais ele tratará. Dos três nomes que estão em seu horizonte, Grossman, Yehoshua e Amós Oz, dois são sabras, israelenses nativos e não mais emigrantes (Grossman e Amós Oz). Esse dado faz toda a diferença e a particularidade dessa condição acaba construindo uma relação com o judaísmo diferenciada. Assim, o conflito árabe-israelense, muito presente na obra de Grossman, acaba por vir à tona e traz um traço do judaísmo antes não existente, que diz respeito à posse da terra.

Os judeus sempre quiseram voltar para Israel, sua terra mítica, mas quando de fato retornam, o ser israelense passa a ser constitutivo do ser judeu, em oposição ao judaísmo diaspórico, em que judeus são nativos de diferentes países mas têm uma relação mítica com Israel, a terra prometida para a qual imigrarão ou não. 
Moacyr Scliar destaca na crônica o caso de David Grossman, escritor e jornalista encarregado por uma revista de fazer uma série de entrevistas sobre os territórios ocupados. As entrevistas resultaram no livro $O$ vento amarelo que, publicado em 1987, causou imediatamente comoção em Israel e outros países. O título alude a uma lenda árabe, segundo a qual um "vento amarelo" soprará do deserto calcinando os inimigos do Islã (p. 101).

Grossman descreve a sombria situação em que viviam os palestinos, dependentes de Israel para conseguir trabalho e abominando a ocupação. É complicado ser israelense e ter que lidar com uma história com a qual individualmente não se concorda. Por outro lado, o judaísmo que se desenvolve a partir daí pode trazer um horizonte de conflitos, sempre que se atribui alguma razão ao inimigo.

O trabalho de Grossman desperta furiosas reações, a ponto de o então primeiro ministro Yitzhak Shamir acusá-lo de distorcer os fatos e de fazer o jogo dos inimigos de Israel. Mas o escritor tinha razão, avalia Scliar. Três meses depois iniciava a intifada, o levante palestino nos territórios que acabou levando, ainda que de forma indireta, às conversações de paz. Grossman funcionou como um profeta, no caso.

Amós Oz é outro escritor que batalha pela paz no Oriente Médio, objeto da crônica de Scliar. Vivendo em Israel e tendo passado pela experiência kibutziana, a ficção de Amós Oz também põe ênfase na necessidade de convívio pacífico entre judeus e árabes:

Dois povos teimosos (judeus e palestinos), dois povos conhecedores do sofrimento e da perseguição, dois povos que mostraram, através de uma luta de gerações, que são capazes de determinação e também de devoção - esses dois povos agora têm a chance de usar essas qualidades na construção de uma casa semisseparada. [...] Existe um longo caminho a percorrer, um caminho cheio de fúria e desapontamento, mas pode-se ver ao longe as primeiras, e hesitantes, luzes da paz. (p. 102) 
Cad. Líng. Lit. Hebr., n. 15, p. 10-16, 2017

Um terceiro escritor incluído na mesma crônica de Scliar é Aharon Appelfeld, europeu sobrevivente do Holocausto que chegou ainda criança a Israel e escreve muito sobre o extermínio do povo judeu e outros temas locais.

É interessante observar a diferença entre judeus israelenses e judeus diaspóricos perante o sionismo. Os que já vivem em Israel, os sabras, posicionam-se pelo simples fato de viver no país, defendendo o Estado - e essa defesa é sua forma de se manterem sionistas. Já os judeus diaspóricos são nativos de outros países e têm um vínculo com Israel; para eles importa que haja paz no país, mas também que o lugar em que vivem e onde nasceram não seja inóspito aos judeus.

Essa dupla pertença projeta modos distintos de posicionamento perante o ser judeu. É interessante, a propósito, mencionar um trecho do poema "Turistas" de Yehuda Amichai, em que há uma visão crítica do israelense em relação ao judeu-turista em Israel:

Eles estão aqui para visitas de condolências; é o que fazem, Sentados no Memorial do Holocausto, fazendo (com) cara séria No Muro das Lamentações, Mas rindo atrás das pesadas cortinas dos quartos de hotel.

O poema prossegue com uma narrativa:

Uma vez eu estava sentado nos degraus perto da Cidadela de Davi com dois pesados cestos a meu lado. Um grupo de turistas estava ali, ao redor de seu guia, e eu tornei-me um ponto de referência: "Veem aquele homem com os cestos? Um pouco à direita de sua cabeça há um arco do período romano". E eu disse a mim mesmo: a redenção virá quando alguém disser a eles: "Veem aquele arco do período romano? Ele não tem nenhuma importância, mas perto dele está um homem que acabou de comprar frutas e verduras para sua família. (p. 103-104).

Gostaria, ainda, de mencionar, à guisa de fecho, uma passagem da crônica "Uma cálida noite de outono de 48" (datada de 30/04/1998), em que Scliar se lembra de si mesmo, um garoto que caminhava por alguma rua do bairro do Bom Fim, quando se dá conta de que as pessoas estavam celebrando. Por que celebravam? Só no dia seguinte ele ficou sabendo: o Estado de 
Israel havia sido proclamado. Ele viu como o orgulho foi se apossando de todos os judeus seus conhecidos, o orgulho, talvez, de uma dignidade recuperada. Mas a guerra havia começado de imediato e o novo Estado parecia desamparado diante de seus poderosos vizinhos. Dia a dia o menino acompanhava o conflito pelo rádio e pelo jornal, destacando sua apreensão com a notícia sobre o envio de armas tchecas a Israel. Não seria contraproducente um apoio comunista? Eis uma questão que, como muitas outras, foi engolida pela história: a guerra terminou, os países comunistas deixaram de apoiar Israel e passaram a atacá-lo e, um dia, deixaram de ser comunistas. Israel venceu de novo seus vizinhos em 1967 e obteve territórios, mas não a paz, que continua sendo, como era em 1948, o grande objetivo.

O kibutz que, para os mais jovens, significava a materialização da utopia socialista, teve seu apogeu e entrou em crise. Em compensação, a ortodoxia religiosa, que antes era mais um objeto de curiosidade, hoje é força política importante em Israel. O trabalho da terra, visto pelos pioneiros como uma forma de redenção de um povo anômalo, perdeu em importância para uma indústria ultrassofisticada. O país exporta tecnologia, uma de suas fontes de riqueza.

Cinquenta anos depois, Moacyr Scliar recorda com saudades do garotinho que caminhava pela rua João Telles no dia em que foi proclamado o Estado de Israel. Ele ia para casa. Nessa mesma data, a nação imaginada pelos judeus renasce das cinzas e deposita-se em um nós coletivo, irmanando relações em tudo distintas.

Como afirma Benedict Anderson (2008, p. 13) em Comunidades imaginadas, as nações se concebem sempre como estruturas de camaradagem horizontal. E é assim que nasce o "nós" coletivo, num laço entre o judaísmo diaspórico e o nacional, relações em tudo distintas que criam pontos em comum - é o que ressaltam as crônicas de Scliar e sua ficção, em sentido mais amplo. 
Cad. Líng. Lit. Hebr., n. 15, p. 10-16, 2017

Para terminar, lembro que desde seus primeiros romances Scliar acompanhou os conflitos e os desdobramentos decorrentes da imigração dos judeus ao Brasil, localizando-se fora e dentro de seu grupo de origem, mas vivendo de dentro a experiência de hibridização de que trata. Assim, o autor, com seu estilo coloquial, a visão crítica da realidade que o caracteriza e a construção de seus heróis fracassados, insere-se na literatura brasileira que vem se desenvolvendo no Brasil nas últimas décadas, destacando-se como o representante mais fecundo desse encontro particular de culturas nas letras brasileiras contemporâneas.

Neste momento, em que Moacyr Scliar já não está entre nós, lembro uma frase do escritor francês Maurice Blanchot que diz: “Quando estou só, não estou”. Destacando o sujeito em paralelo com o processo de criação, pode-se dizer que o escritor trabalha sozinho e desaparece na escrita.

\section{Bibliografia}

ANDERSON, Benedict. Comunidades imaginadas. São Paulo: Companhia das Letras, 2008. p. 13

SCLIAR, M. A nossa frágil condição humana: crônicas judaicas. São Paulo: Companhia das Letras, 2017. 